\title{
Study of Some Key Elements of Design and Selection of an Educational Video Game Conducive to the Moroccan Secondary School Learners: The Motivational Profile and Pedagogical Coherence
}

\author{
Jalal Khouna ${ }^{1, *}$, Ahmed Rhazal ${ }^{1}$, Lotfi Ajana ${ }^{2}$, Abdelilah El Mokri \\ ${ }^{1}$ LIRDIST, Interdisciplinary Laboratory of Research in Didactics of Sciences and Technology, Faculty of Sciences Dhar Mahraz, Sidi \\ Mohammed Ben Abdellah University, B.P. 1796, Fès-Atlas 30003, Morocco \\ ${ }^{2}$ LIPI, Laboratory of Computer and Interdisciplinary Physic, ENS (Ecole Normale supérieure), Sidi Mohammed Ben Abdellah \\ University, B.P. 1796, Fès-Atlas 30003, Morocco
}

Received January 23, 2020; Revised February 29, 2020; Accepted March 12, 2020

Copyright $\bigcirc 2020$ by authors, all rights reserved. Authors agree that this article remains permanently open access under the terms of the Creative Commons Attribution License 4.0 International License

\begin{abstract}
Educational video games are being used increasingly in teaching physics. They offer learners a fun and convivial learning environment. However, the use of an educational video game genre that is ill-suited to a type of learning situation or inconsistent with the learners' motivational profile influences the effectiveness of its use in the classroom. In this context, this article deals, on the one hand, with the coherence between the genre of video games and the type of learning situation found in the context of the competency-based approach. On the other hand, it presents the results of a survey to describe the Moroccan learners' motivational profile in video games. The results show that the games should be adapted to each type of learning situation, designed and chosen to meet the learners' interest and avoided when learners are not interested in the genre of the games. It is also pointed out that most of learners prefer to use video games at the level of the explanation of the lessons and the exercises. In light of this research, we have made a number of recommendations for choosing and designing an educational video game.
\end{abstract}

Keywords

Competency-based

Learning Situation

Educational Video Games, Approach, Motivational Profile,

\section{Introduction and Research Question}

In Morocco, video games are an ever-evolving leisure. In fact, a survey on ICT access and usage by households and individuals in Morocco carried out by the National Telecommunications Regulatory Agency (ANRT) in 2015 indicates that games and entertainment represent one of the favorite content types for $57 \%$ of Internet users [1]. In addition, among all types of games, video games are the most preferred by $73 \%$ of Moroccan learners [2]. Furthermore, the video game becomes an important vehicle for education. This kind of game is called an educational game [3].

For game-based learning, careful construction or selection of a game is essential [4], it is not enough to place an educational video game in a learning situation so that it finds its place and the learners integrate harmoniously with it in classroom. On the contrary, in order to allow an educational video game to deliver its educational potential, it is important to study its pedagogical coherence with the types of learning situations that serve as a basis for implementing learning in the competency-based approach [5]. We must also ensure that the genre of the video game is motivating for Moroccan learners. In fact, the goal of educational games is to provide users a high level of motivation and ample challenges [6].

Indeed, educational game selection should depend on the type of learning situations that were found within the framework of the competency-based approach. We can therefore ask ourselves the following question: Which kind of educational game for what type of learning situation?

The analysis of the compatibility of the game genre with the learning situation is the first line of this research, but this is not sufficient to start using or designing an 
educational game. It is therefore important to propose and design for learners' video games that are best adapted to their motivational profiles. In this sense, the second research objective was to explore Moroccan learners' opinions concerning video games, in order to know their practices and the genres that were highly motivating for them.

By crossing the results of the motivational profile in video games with the analysis of the pedagogical coherence of educational video games according to each learning activity, we can on the one hand give designers the possibility to make methodological choices when designing an educational game. On the other hand, teachers will be able to choose a motivating educational game for the learner and take into account the requirements of each type of learning situation. The current work complements a previous study that focused on the use of educational games in teaching physics in the Moroccan context [7].

\section{The Pedagogical Coherence of Educational Games in Teaching and Learning Physics}

Using educational video games in the classroom places the learner at the centre of the learning process, whether individually or collectively. In fact, games enhance learners' motivation and autonomy and allow them to develop high-level skills by emerging in complex learning situations [8]. One of the strong points also of these pedagogical tools is the creation of a positive attitude towards the subjects taught [2].

However, activities based on educational games are not without difficulties. The most important limitation on the use of the educational games is the relevance of the game choice [9,10] Indeed, there are different types of educational games based on different learning theories: behaviorists, constructivists, and etcetera. [11] And some of them may not meet the requirements of the competency-based approach. Moreover, the existing educational video games vary greatly in their quality according to the intentions of their designers; it was around this frame of reflection that we chose to study the coherence of educational video game genre with each type of learning situation.

Learning in the competency-based approach is essentially based on the individual's ability to mobilize a set of resources in a problem situation in order to resolve it. To this end, we will present for the learner different situations that he can gradually learn to identify the necessary resources, to mobilize them and to organize them together for solving the problem situation [12]

In fact, when we talk about skills, we implicitly mention two fundamental elements [13]:
- Resources, which constitute an ensemble of knowledge, know-how and social skills that the learner will have to mobilize them in seeking solution to the problem situation.

- $\quad$ situations in which the learner will have to mobilize all of his or her resources

In this sense, and for implementation of learning, Xavier Roegiers talks about four different learning situations: situations of exploration, situation of structuration, situation of application, and situation of integration. [5]

As a learning situation, the game involves modelling a given reality. Indeed, the model implemented in the game results from the transposition of a real situation in the context of the game [14]. Educational games offer inductive learning situations, which are therefore particularly conducive to knowledge creation, but each game genre must be compatible with the learning situation in which the learner is immersed. For example, a game based on training cannot be used at the beginning of the lesson where the learner has not yet been sufficiently explored the necessary notions. In this sense, we have built the analysis model below based particularly on educational video games genre (gamplay) and the characteristics of each learning situation. It should also be noted that we have chosen to limit ourselves to the educational video games genre, which are most, used in teaching and learning physics.

\subsection{Situation of Exploration and Appropriation}

This is the starting point in each learning sequence. Therefore, it must be ensured that it is motivating for all learners; it must also allow each learner to appropriate the problem in the situation and embark on a process of reflection to solve it. Indeed, it is a situation of discovery and exploration destined to destabilize learners where they invest their resources and questions about the methods and strategies for solving the problem.

In the case of the situation of exploration, the discovery and exploration games are the most suitable for several reasons: First, this type of video game were designed for allowing learners to advance and explore a new scientific field $[15,16]$ or to revisit their conceptions before starting a new lesson [17]. Another characteristic of this games genre is that the problems do not have predefined solutions; there are several avenues for research and investigation. Therefore, the learner will mobilize several distinct strategies while remaining true to the knowledge of the scientific phenomenon under study $[15,16]$. Adventure games are also very useful in this type of situation, especially those characterized by thoughtful exploration, such as the case of the scientific adventure game Odyssey for learning physics [18]. Moreover, in adventure games, the complexity of the scenario, the atmosphere, the graphic and the sound quality outweigh 
the action itself [19], which helps to motivate and capture the learners' interest at the beginning of the learning sequence. In fact, the learner embarking on a discovery adventure, is often motivated to surpass challenges [20].

\subsection{Situation of Structuration}

Situation of structuration is intended to structure the resources. Learners have an opportunity to solve the problem using their own strategies and appropriate approaches, and thus they verify and validate the adopted solutions. In fact, the learner compares, develops techniques and acquires new knowledge. This is a learning situation that we can emerge new concepts; moreover, it is a passage from the action to the formulation basing on the problems faced by the learners in situation of exploration. The problems raised are sequential and well defined according to the learning objectives. It is a very important phase in order to reach a constructive process of reflection about the notion addressed.

The aim of this type of situation is to bring the learner beyond simple exploration to engage in an explicit learning process by structuring and mobilizing his resources. The games genre that are conducive to use in this type of situation are strategy games, action-adventure games and puzzle games, for several reasons.

The structuring of knowledge refers to the construction and organization of knowledge, in order to understand a concept, a principle, a procedure or a situation [21]. Games promote structuring and transfer of knowledge by contributing to the reinforcement of subject specific knowledge [22].

Indeed, strategy games provide an opportunity for learner to try several strategies during play, which allow him to become more familiar with new situations in a constructivist way [17]. Moreover, they are based on the player's reflection and his ability to make the right choices in order to move forward [23]. The structuring of knowledge and the construction of concepts can be carried out during the reflexive phases of the game, the learner retains his freedom to act, to make decisions, to make his tests, and to build his own experience. The example that we can give is the game Circuit Warz dedicated to learning some concepts of electronics [7].

Concerning action-adventure games, the alternation between moments of exploration related to the adventure side of game, research and problem solving related to the action side [23] is beneficial to use in the structuring situation. It is an opportunity that will allow learners to explore, then reflect on each action and develop strategies. The example that we can cite is the educational game Mecanika for learning mechanical concepts.

Mind games which include labyrinth games, Hidden Objects games, and puzzle games, [23] allow learners to think about each action and adopt logical reasoning to solve a problem or overcome a level in the game. In fact, the use of this game genre allows learners to develop their scientific skills, their social skills, and to understand the scientific concepts [24] which will bring more in terms of structuring resources for learners. The example we can cite is the online game Supercharged for learning electrostatic concepts.

In the three genres of the game that we have proposed to use in the structuring situation, learners can invest their conceptions so that they become aware of their inadequacy in some cases. As a result, they will seek to correct them, moreover, the learner takes a step back after each action, which leads to a good structuring of knowledge.

\subsection{Situation of Application}

It is a learning situation where the learner will use his new learning to measure the degree of mastery; it is a direct application of what has been learned. Indeed, the learner will be led to repeat to appropriate the solutions, memorize them and advance. He often uses the effective strategies previously found so that he is not only a situation of imitation but also rather a skill transfer.

Educational games that are conducive to this type of situation depend on the activities that will be implemented as parts of this learning situation: we can use memory, simulation, adventure and strategy games. They will allow the learner to apply what he has already learned in previous activities and to realize numerous repetitions, in order to master content and procedures. This is the stage of verification and application of resources acquired.

The purpose of simulation games is to enable the user to perform a particular task or to study a phenomenon that has been reproduced in a virtual environment [25]. In physics, these games give learners the opportunity to develop an intuitive understanding of physical phenomena and abstract ideas [26]. Due to the importance of memorization in the application phase and mastering knowledge, the use of games is desirable to activate previous knowledge and acquire new knowledge [27]. Moreover, the use of video games has shown a better efficiency of memorizing procedures [28]. Concerning the role of strategy, mind and adventure games - which we spoke previously - in this type of learning activity lies in mastering of procedures, structures and learning contents [29].

The diversity of game gender is due to the learners 'activities found in this situation: application, conceptualization, memorization, exploration, mobilization and restitution activities.

\subsection{Situation of Integration or Reinvestment Situation}

The integration situation is exploited to learn how to integrate a set of resources. In fact, it invites learner to use 
previously learned knowledge in new and complex situations [30]. It is a situation of reinvestment of acquired knowledge in a new context different from initial learning. In fact, the learner will mobilize his knowledge and know-how in various situations, with a view of implementing, strengthening, consolidating and memorizing of knowledge.

Using games in learning develops the learner's ability to establish links and transfer knowledge in other contexts, which allows the integration of knowledge [22]. Strategy, action-adventure, and Role-play games based on mission are the three game genres that can be used in this type of situation.

In fact, the player is charged with managing the progress in the game. He advances after each goal is reached. We can take advantage of this kind of gameplay to gradually integrate into each mission a physical concept or an additional difficulty in order to propose new challenges to the learners in relation to the knowledge that can be taught. Moreover, the present feedbacks in these games favour this integration of knowledge [31]. In these games, learners are autonomous, so they are encouraged to take initiatives and develop their own strategies [32]. For example, in the educational role-playing game Radon Dungeons, the player fulfills missions that will enrich his knowledge in physics and chemistry.

However, the pedagogical coherence of the game genre with the learning situation is not the only element taken into consideration when choosing or designing an educational video game, because if the learner does not feel the urge to play all this will remain an empty shell.

\section{The Importance of the Learners' Motivational Profile in Educational Video Game Design}

Playing in general can lead to a state of flow [33] which seems quite adaptable to video games [34]. The concept of flow is a state of complete immersion in an activity. It happens when a player's skills are fully involved in overcoming a challenge that is just about manageable, so it acts as a magnet for learning new skills and increasing challenge [35]. Indeed, this state of flow describes the challenge that the player will face.

Although the adaptation of the difficulty according to the abilities of the player is effective in order to improve the appreciation of the game [36], some players report a preference for different degrees of challenge [37]. Therefore, the flow does not seem able to be described by a linear relationship between the difficulty of the game and the player's skills that are not similar for all players. Rather, several factors, including the player's preferences, would modulate this relationship [38].

The need to take into account the motivational profile of learners is a reality that we find in several models of educational video game design, such as de Freitas's design model [39] and Kumar's model [40]. Indeed, the failure of about $80 \%$ of games is mainly due to design problems centered on information and / or technological devices [41], in this sense Kumar proposes a design model that places the user at the center of this design process [40].

Generally, the more the game meets learners' expectations and needs, the more the chance that the game will hold the learners' interest and motivation. In fact, a game that is ill-adapted to the player preferences and needs can often lead to a physical and mental tiredness, and thus to a decline in immersion and appreciation of the game [42]. Therefore, it is important to take into consideration learners preferences in terms of video games genre.

In addition, the identification of learners' profiles is one of the main elements on which the design model of Sara De Freitas and Martin Oliver are based, in order to take into account the learners specificities in the needs analysis phase [39].

It is, therefore, important to hear and respect the video game preferences of learners if we don't want to miss the major benefits of educational games such as motivation and engagement that are crucial to the learning process. In this sense, this exploratory study aims to identify the gamer motivation profile, in order to be used in design or in selection of an educational game conducive to the Moroccan context.

\section{Research Methodology}

\subsection{Research Approach}

In this study, we have adopted a quantitative approach to provide a better description of the Moroccan gamer motivation profile in the video game.

\subsection{The Target Population}

The population targeted by our study is 300 secondary school learners of physics, from Fez city. However, we received 289 completed surveys in response.

\subsection{The Study Tool}

We administered an anonymous questionnaire to secondary school learners of physics, to ensure that responses are as honest as possible

\subsection{Development of Research Tool}

We have built our survey questionnaire based on a review of the literature that we have just described in this article and the previous studies related to this research topic. The main questions of this questionnaire are related 
to:

- The time spent on playing video games

- The video game genres played by learners

- The devices used to play

- The Game modes

- $\quad$ The most preferred course part for using educational video games

\subsection{Research Procedure}

The sample in our survey was very heterogeneous, composed mainly of secondary school learners belonging to different high schools in Fez. The distribution and the recovery of the questionnaire are done in cooperation with physics teachers.

\subsection{Type of Data Analysis}

The data resulting from the search is responses to the questionnaire, since the research is exploratory and we have no hypothesis to verify, we reviewed and analyzed the responses using a simple descriptive statistical study.

\section{Results and Discussion}

The information collected from Moroccan learners concerning the learner motivation profile in video game has allowed us to present the following statistical results.

\subsection{The Time Spent on Playing Video Games}

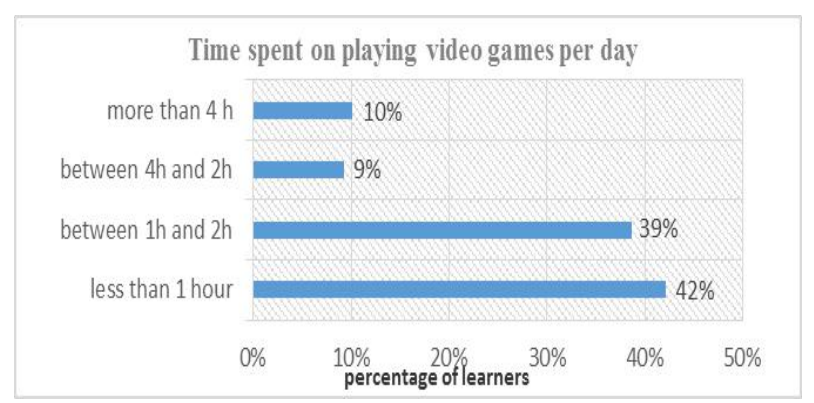

Figure 1. Learners replies to question linked to the time spent on playing video games per day.

Time spent playing is an important concern for designers and teachers; it should not be isolated from the design and choice of the game. Indeed, game passion and the challenges posed by video games can require considerable amount of time from learners.

This result can be exploited by game designers at the level of game session time. Indeed, the results show that for almost $42 \%$ of these learners, the game session should last no more than one hour. Moreover, this result does not seem indicative of learner's preferences, but rather the importance they place on video games [43].

\subsection{The Game Devices}

When we talk about video games and the gamer motivation profile, we must take interest in the devices used to play. In fact, there is not one video game device, and each player has his own preferences. In this sense, it is important to have the opportunity to express their views on this subject, in order to determine the most utilized game devices.

The result is as follows:

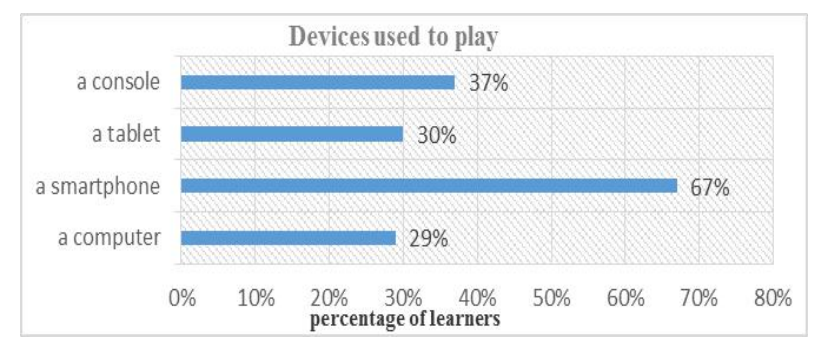

Figure 2. Learners replies to question linked to the devices used to play

The result obtained for this question is very interesting. Indeed, the smartphone is the most used by Moroccan learners to play video games $(67 \%)$, followed by consoles $(37 \%)$, then tablets $(30 \%)$ and computers (29\%), with quite similar percentages.

This is due to a combination of factors, among which is the increasing use of smartphones, particularly for young Moroccans; in fact, according to a survey of ICT indicators collection, conducted by the ANRT in 2018, (75.7\%) of those equipped with a mobile phone have a smartphone, about 22.5 million people. The survey also showed that young people are the largest category using smartphones [44].

On the international scale, we can cite the result of a video game survey conducted by the Entertainment Software Association (ESA) in USA, on a sample of about 4,000 Americans in 2018, which showed that (60\%) of video game players like to play on the smartphone, and $(40 \%)$ prefer other supports such as consoles or computers. It is almost the same in France; smartphone is the most used to play video games. Indeed, according to the results of the Statista Global Consumer Survey for the year 2018, $(46 \%)$ of French people play video games on smartphones, against $(40 \%)$ on computers and $(27 \%)$ on consoles [45].

One of the reasons that can justify the spread of this phenomenon is the portability of smartphones, which represents a major advantage for players; they can play anywhere and anytime. In addition, there is no additional content to pay compared to other game devices. Therefore, it seems perfectly normal that this game device should gain quickly the attention of video game fans.

In this sense, the designer might benefit from this result, in order to make an educational video game conducive to the Moroccan learners expectations in terms of game devices. 


\subsection{The Game Mode}

The third question concerns the game modes, with which the player wants to play video game. Since to our knowledge in video games there is not only one game mode, but in fact, there are different modes from which players can choose if this option is available on the game. In this sense, we can cite four game modes depending on the number of players:

- Single-player: In this mode there is only one player who intervenes throughout the game

- Two-player: This game mode allows two players to intervene during the game.

- Multiplayer: In this game mode, several players intervene at the same time or per turn.

- Massively multiplayer: this game mode allows a higher number of participants (hundreds / thousands) to play simultaneously in the same environment. In most cases, this mode requires the presence of internet.

The learners' responses give the following results:

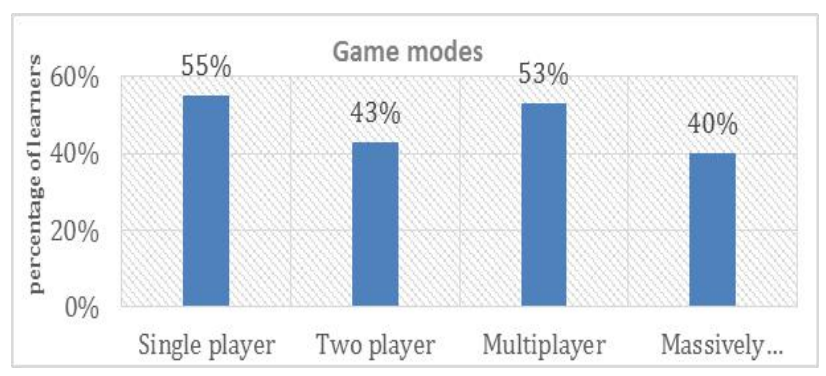

Figure 3. .Learners replies to question linked to the game modes

Based on the results, we cannot draw firm conclusions about the preferred game mode for Moroccan players. Indeed there is a great diversity, which depends on several factors (internet access, game supports. . .).

This result can be seen in two different angles. In fact, at the design level we can think of diversifying game modes since there is not a dominant game mode for Moroccan learners and, consequently, diversifying learning method. The teachers can then get learners working individually, in pairs, or in small groups. Moreover, in the problem situation we can use two different solving approaches, an approach based on the independent method by using the game mode single, and the other approach based on the interdependent or collaborative method by using game mode two-player and multiplayer.

The percentages of the game mode multiplayer $(53 \%)$ and massively multi-player $(40 \%)$ are important, this result can be explained by the increasing use of social networks. In fact, online games often require that players should be part of team to progress in the game and to remain on top.

Moreover, according to an ANRT survey conducted in 2013, (57\%) of Moroccan individuals like to play video games on social networks, the culture of online video games is growing [46], as well as, sometimes, some video games are only accessible through social networks.

It is also important to note that multiplayer modes can develop the sociability of players, because they learn teamwork strategies, collaborate with each other to overcome obstacles and they share a lot information around the game.

\subsection{Video Game Genres Played by Learners}

The use of video games is widespread, which raises questions about the different game genres and what genre games are currently popular. Indeed, faced with the diversity of video game genres available to the hands of learners, we are drawn to explore the points of view of learners on this subject. We use the results of this question to help us describe the learner motivation profile in video game.

The results are as follows:

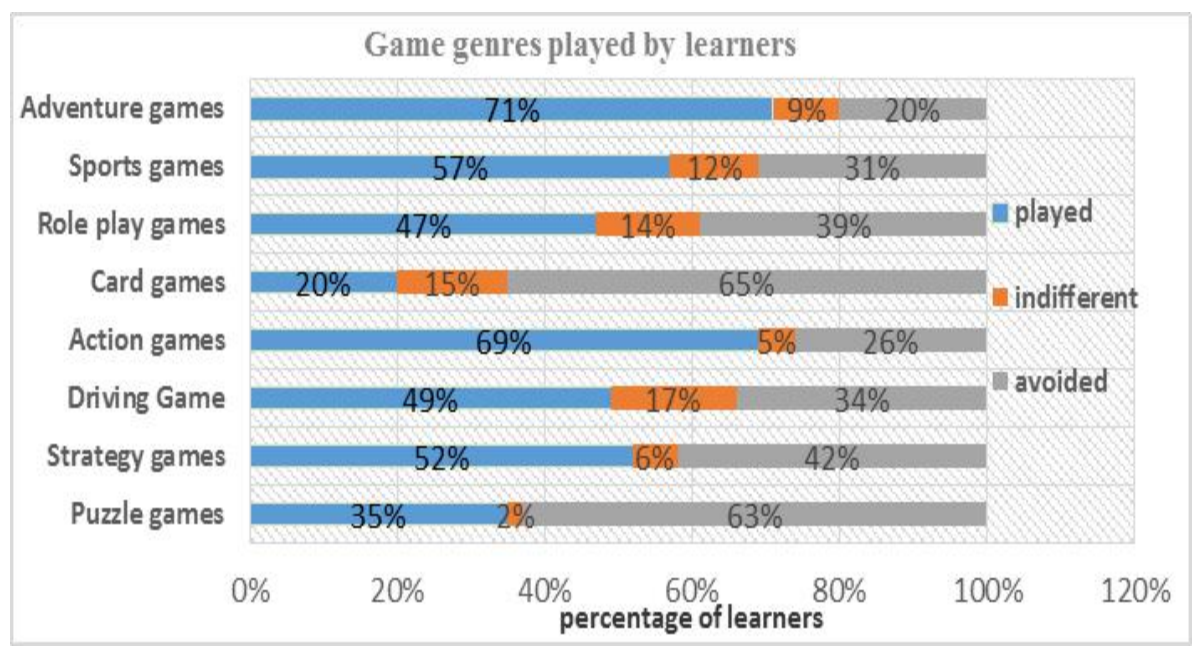

Figure 4. Result of the video game genres played by learners 
According to the results of the histogram above, the first two video game genres most played by our sample are respectively the adventure genre $(71 \%)$ and the action genre $(69 \%)$. In second position, we find sports game $(57 \%)$, strategy games $(52 \%)$, role-playing games $(47 \%)$ and driving games $(49 \%)$. In contrast, fans of card games and puzzle games represent low percentages of learners.

Similarly, a study conducted by Crucial in France, showed that the two dominant video game genres are adventure games and action games. Indeed $58 \%$ of the French people prefer to play action games and 50\% adventure games. [47]

Moreover, although the results found are in good agreement in general terms with the results of other international surveys of the same type, an examination in relation to the Bartle taxonomy of player types will allow us to say more about the typology of Moroccan players.

The best-known and most used motivational model for the game is the Bartle model [48], which is a classification of video game players according to their preferred actions within the game. Indeed, Bartle talked about four of players: Achievers, Explorers, Socializers, and Killers [49] (See figure 5).

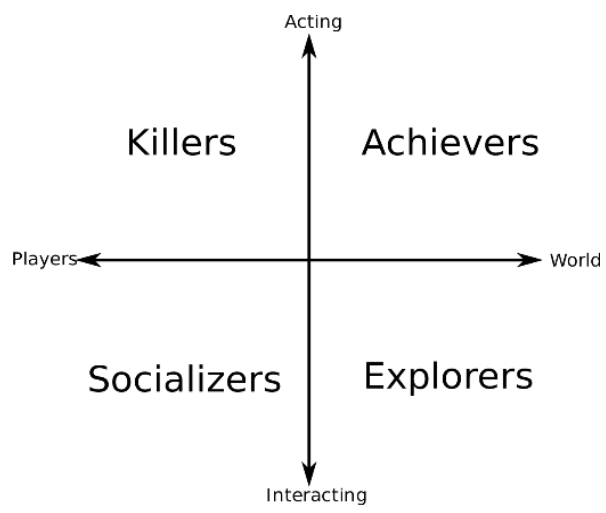

Figure 5. The Bartle taxonomy of player types

In accordance with the results of the question concerning video game genres, the dominating player's typologies are the Explorers followed by the Achievers. Indeed, the video game genres most played by our sample are respectively adventure genre $(71 \%)$, and action genre $(69 \%)$. The fact, which may in part explain these preferences, is the nature of the activities that they present these game genres. For example, the adventure game is essentially based on research and exploration activities, dialogues and puzzle solving. Concerning adventure games, it focuses on reflex activities and on adopting a precise set of actions to achieve some objectives. In addition, these two genres offer players many choices in terms of the game scenario.

\subsection{The Most Preferred Course Part for Using Educational Video Games}

The choice of course part in which the learners want to use educational video games aims to maximize their satisfaction and identify their needs regarding the studied lessons.

The result is as follows:

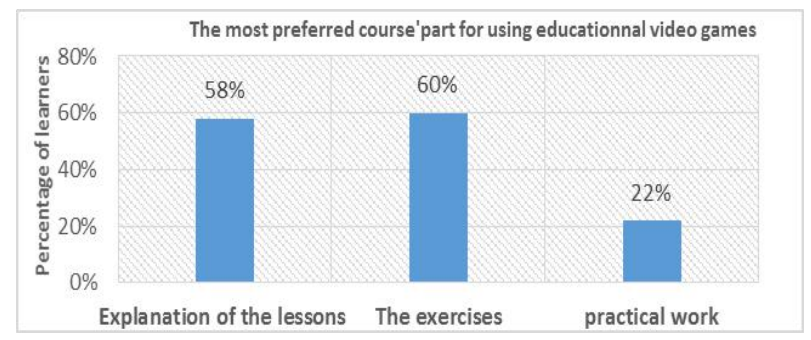

Figure 6. Result of the question related to the most preferred course' part for using educational video games

As expected, the above result shows that most learners do not want to use educational games in practical work session (only $22 \%$ ). On the other hand, the need was felt to use educational video games at the level of the explanation of the lessons (58\%) and the exercises (60\%). Moreover, some exercises of physics can be considered stressful, when the concentration requested is too high and the learner's memory is too much solicited, or when there is a great difficulty in understanding physical phenomena. However, it will be less stress when learners use educational games for solving exercises. In fact, it is one of the educational and motivational means of getting learners to act without stress in their learning.

In this sense, we can think of tutoring based on educational games through websites, especially since $70 \%$ of Moroccan learners say that they use tutoring online [50]. Furthermore, and through the result for this question, Moroccan learners expect that educational video games will allow them to solve their exercises and improve the understanding of their lessons.

\section{Conclusions and Recommendations}

This study allowed us, on the one hand, to highlight the importance of coherence between the educational video game genres and the types of learning situations found in the competency based-approach, in order to succeed their integration in the Moroccan context. On the other hand, it opens the door to the design and the choice of educational games, taking into account the specificity of the Moroccan learners. In this sense, we conducted an exploratory study that led us to describe the Moroccan learners motivation profile in the video game. In the light of this study, the following recommendations can be made:

- The choice of an educational video game must depend on the learning situation in which it is used. In this sense, teachers are recommended to use educational games adapted to each type of learning situation for an effective implementation of the competency-based approach. 
- The educational games must be part of an educational tool in which the Moroccan learners' interest is placed at the centre of their design and their choice.

- Based on the research results, we can say that offering Moroccan learners learning situations based on exploration games and action games would be very motivating.

- The exploratory study showed that learners have very little interest in puzzle games; it is advisable to avoid their use in the classroom.

- It is recommended to the designers to diversify the game modes during the design since the Moroccan learners play on several modes. Moreover, the session of the game should not exceed one hour.

- We can envisage tutoring based on online educational games since a large number of Moroccan learners want to work with these tools in the exercises.

- We have to think about taking advantage of smartphones for learning purposes.

Finally, it should be noted that the results of the exploratory study do not present a detailed and complete model of the Moroccan learners motivation profile in the video games, we were only interested in certain elements that we think are relevant. Moreover, our population may have specific unstudied characteristics, and it would be beneficial to draw a sample of different environments in future work.

\section{REFERENCES}

[1] ANRT- National Telecommunications Regulatory Agency, (2015) The Annual Report of 2015, published on the web pages of ANRT -https://www.anrt.ma/sites/default/files/ rapportannuel/rapport_annuel_anrt_2015_vf.pdf

[2] Khouna, Jalal \& Ajana, Lotfi \& Rhazal, Ahmed \& Hajjami, Abdelkrim. (2017). Introducing Educational Games in the Teaching of Physics in Moroccan Secondary Schools. IOSR Journal of Research \& Method in Education (IOSRJRME). 07. 19-28. 10.9790/7388-0704011928.

[3] Sun, H. (2017). Design of Education Application based on Shiva 3D Platform. International Journal of Emerging Technologies in Learning (IJET), 12(04), pp. 200-207. doi:http://dx.doi.org/10.3991/ijet.v12i04.6685

[4] Lothian, J., \& Ryoo, J. (2013). Critical Factors and Resources in Developing a Game-Based Learning (GBL) Environment Using Free and Open Source Software (FOSS). International Journal of Emerging Technologies in Learning (IJET), 8(6), pp. 11-20. doi:http://dx.doi.org/10.3991/ijet.v8i6.2918

[5] Roegiers, Xavier. « Chapitre 8. Travailler la Pédagogie de l'Intégration au quotidien de la classe ", Curricula et apprentissages au primaire et au secondaire. La Pédagogie de l'Intégration comme cadre de réflexion et d'action, sous la direction de Roegiers Xavier. De Boeck Supérieur, 2011, pp. 223-256.

[6] St-Pierre, R. (2010). Des jeux vidéo pour l'apprentissage. Distances, $\quad 2010, \quad$ 12(1), 4-26. https://itmedmod.ca/sites/default/files/pdf/v12n1b.pdf

[7] Jalal, K., Lotfi, A., Ahmed, R., \& Abdelilah, E. (2019). Are Educational Games Engaging and Motivating Moroccan Students to Learn Physics? International Journal of Emerging Technologies in Learning (IJET), 14(16), pp. 66-82. doi:http://dx.doi.org/10.3991/ijet.v14i16.10641

[8] Eric Sanchez, Muriel Ney, Jean-Marc Labat. Jeux sérieux et pédagogie universitaire: de la conception à l'évaluation des apprentissages. Revue Internationale des Technologies en Pédagogie Universitaire, Conférence des recteurs et principaux des universités du Québec [CREPUQ], 2011, Journées scientifiques "Pédagogie Universitaire Numérique", 8 (1-2), pp.48-57. ff10.7202/1005783arff. ffedutice 00613840

[9] Wastiau, (Patricia); Kearney (Caroline) et Van Der Berghe (Wouter), (2009), Quels usages pour les jeux électroniques en classe? European Schoolnet.

[10] Wix, (Anne), (2012), Jouer en classe, est-ce bien sérieux? Bilan de l'expérimentation académique sur les usages de jeux sérieux au collège et au lycée. Académie d'Aix-Marseille.

[11] Egenfeldt-Nielsen, (Simon), (2006), Overview of research on the educational use of video games. Digital Kompetanse, 1(3), pp.184-213

[12] ROEGIERS, X. (2003), Des situations pour intégrer les acquis, Bruxelles: De Boeck.

[13] Roegiers, Xavier. (2006). La pédagogie de l'intégration en bref. Rabat: The Moroccan Ministry for Education. http://htarraz.free.fr/sakwila/prof/pedagogieROGIERES.pd f

[14] Eric Sanchez. When games meet learning. IIGWE2011, Aug 2011, France. pp.9-13. ffhal-00618291

[15] Cooper, S., Treuille, A., Barbero, J., Leaver-Fay, A., Tuite, K., Khatib, F., Snyder, A. C., Beenen, M., Salesin, D., Baker, D., Popović, Z. and Foldit players (2010). The challenge of designing scientific discovery games, Proceedings of the Fifth international Conference on the Foundations of Digital Games, FDG 2010, New York, NY, pp. $40-47$.

[16] Good, B. M. \& Su, A. I. (2011) Games with a scientific purpose. Genome Biology, vol. 12, no. 135, pp. 1-3

[17] Sauvé, L., Kaufman, D. (2010). Jeux et simulations éducatifs: Études de cas et leçons apprises. Presses de l'Université du Québec.

[18] Odyssey Game - the story of science. 2018 published on the web pages http://theodysseygame.com/

[19] Perron, Yolande.Vocabulaire du jeu vidéo dictionnaire terminologique de l'Office québécois de la langue française $-2012$

p ; https://www.oqlf.gouv.qc.ca/ressources/bibliotheque/dic tionnaires/20120701_jeu_video.pdf 
[20] Natkin, S. (2009). Du ludo-éducatif aux jeux vidéo éducatifs.

Les dossiers de l'ingénierie éducative, 65, 12-15.: http://www2.cndp.fr/archivage/valid/139674/139674-1840 2-23850.pdf

[21] Sauvé L., Renaud L. et Kaufman, D (2010). L'efficacité des jeux et des simulations sur l'apprentissage. Québec, Québec: Presse De l'Université du Québec.

[22] Loisier, J. (2015). Étude sur l'apport des jeux sérieux pour la formation à distance au Canada francophone. http://www.refad.ca/documents/Etude_Jeux_serieux_en_F AD.pdf

[23] Hermès -« Typologie des jeux vidéo », La Revue, vol. 62 , no. 1, 2012, pp. 15-16

[24] Adeyemo, Sunday A. et al. "An Investigation into the Influence of Using Puzzles in the Teaching of Physics on Senior Secondary School Students' Achievement in Selected Topics.” (2013).

[25] Nour El mawas. (2013). Architecture pour la co-conception des jeux sérieux participatifs et intensifs en connaissances. published doctoral thesis, university of technology, Troyes.

[26] Squire, Kurt \& Barnett, Mike \& Grant, Jamillah \& Higginbotham, Thomas. (2004). Electromagnetism supercharged! Learning physics with digital simulation games. Proceedings of the 6th International Conference on Learning Sciences.

[27] De-Marcos, L., Garcia-Lopez, E., et Garcia-Cabot, A. (2016). On the effectiveness of game-like and social approaches in learning: Comparing educational gaming, gamification \& social networking. Computers \& Education, 9599-113

[28] Zacks, J. M., \& Tversky, B. (2003). Structuring information interfaces for procedural learning. Journal of Experimental Psychology: Applied, 9(2), 88100.

[29] Frété, C. (2002). Le potentiel du jeu vidéo pour l'éducation. published Master thesis, University of Geneva, Geneva. http://tecfa.unige.ch/perso/frete/memoire/memoire-cath.pd f

[30] Gérard, F.-M. et Roegiers, X. (2003). Des manuels scolaires pour apprendre à concevoir, évaluer, utiliser. De Boeck et Larcier s.a., Bruxelles

[31] Séverine Erhel, Eric Jamet. Comprendre les effets des Serious Game Éducatifs sur l'apprentissage et la motivation. Le numérique en sociétés: actes du 9e Séminaire M@rsouin, tenu à Bénodet, les 26 et 27 mai 2011 / sous la direction de Godefroy Dang Nguyen \& Priscillia Créach, l'Harmattan, pp.177-194, 2012, 978-2-296-99211-5. ffhal-01784184

[32] Eric Sanchez, Muriel Ney, Jean-Marc Labat. Jeux sérieux et pédagogie universitaire: de la conception à l'évaluation des apprentissages. Revue Internationale des Technologies en Pédagogie Universitaire, Conférence des recteurs et principaux des universités du Québec [CREPUQ], 2011, Journées scientifiques" Pédagogie Universitaire Numérique", 8 (1-2), pp.48-57. ff10.7202/1005783arff. ffedutice $00613840 \mathrm{f}$

[33] Csikszentmihalyi, M. (1990). Flow: The psychology of optimal experience. New York: Harper and Row

[34] Hull, D.C., Williams, G.A., \& Griffiths, M.D. (2013). Video game characteristics, happiness and flow as predictors of addiction among video game players: A pilot study. Journal of Behavioral Addictions, 2, 145-152.

[35] Csikszentmihalyi, M. (2000). Beyond boredom and anxiety. Jossey-Bass

[36] Andrade, G., Ramalho, G., Gomes, A. S., \& Corruble, V. (2006). Dynamic Game Balancing: An Evaluation of User Satisfaction. AIIDE, 1, 3-8.

[37] Alexander, J. T., Sear, J., \& Oikonomou, A. (2013). An investigation of the effects of game difficulty on player enjoyment. Entertainment Computing, 4(1), 53-62.

[38] Bergeron-Boucher, Jérémy (2016) -Identification des motivations pour le jeu vidéo: Revue des typologies des joueurs -published Master's degree in psychology, University of Laval, Laval.https://corpus.ulaval.ca/jspui/bitstream/20.500.1179 4/26941/1/32687.pdf

[39] De Freitas S., Oliver M., 2006, How can exploratory learning with games and simulations within the curriculum be most effectively evaluated? In Computers and Education, Volume 46, Issue 3, pp. 249-264.

[40] Kumar J. M., Herger M., 2013, Gamification at Work: Designing Engaging Business Software, The Interaction Design Foundation, 168 p., Aarhus, Denmark, ISBN 8792964079.

[41] Florent Delomier. Jeux pédagogiques collaboratifs situés: Conception et mise en oeuvre dirigées par les modèles. Autre. Ecole Centrale de Lyon, 2013. Français. <NNT: 2013ECDL0052>. <tel-00995808>

[42] Qin, H., Rau, P. L. P., \& Salvendy, G. (2010). Effects of different scenarios of game difficulty on player immersion. Interacting with Computers, 22(3), 230-239

[43] Bateman, C., Lowenhaupt, R., \& Nacke, L. E. (2011). Player typology in theory and practice. In Proceedings of DiGRA

[44] ANRT, (2018) - National Telecommunications Regulatory Agency- ICT indicators collection survey within households and individuals at the national level for 2018 -Morocco-https://www.anrt.ma/sites/default/files/publicati ons/enquete-tic-2018.pdf

[45] ESA, (2018) Entertainment Software Association - U.S. adults are spending big on video games, playing mostly on smartphones. published in May 2019 by Hilary Russ on Reuters.

[46] ANRT, (2013) - National Telecommunications Regulatory Agency- ICT indicators collection survey within households and individuals at the national level for 2013 -Morocco-https://www.anrt.ma/sites/default/files/2013 en quete_TIC_syn_fr_0.pdf

[47] Crucial study carried out online with a panel of 6000 people in Europe (2000 for France), in July 2018, in collaboration with "3GEM Research \& Insights".

[48] Schell, J. (2014). The Art of Game Design: A book of lenses. CRC Press. 
[49] Bartle, R. (1996). Hearts, clubs, diamonds, spades: Players who suit MUDs. Journal of MUD research, 1(1), 19.

[50] Rhazal, A., Ajana, L., Khouna, J., \& Hajjami, A.E. (2018). Private Tutoring and Internet Use Case of Moroccan Pupils in Qualifying Secondary Education in Urban Area." IOSR Journal of Research \& Method in Education (IOSR-JRME), vol. 8 , no. 2 , 2018, pp. 34-46 